- The UK Child Dental Health survey of 2003 demonstrates an increasing awareness of oral health among parents of all age groups of children, but there are still social class differences.

- Between half and two thirds of all children reported using electric toothbrushes, and the use of mouthwash and sugar-free gum was reported by over $40 \%$ of 15 -year-olds.

- Parents' preferences for treatment of permanent and primary teeth differ, with over $90 \%$ preferring a restorative option for permanent teeth compared with $28 \%$ for primary teeth.

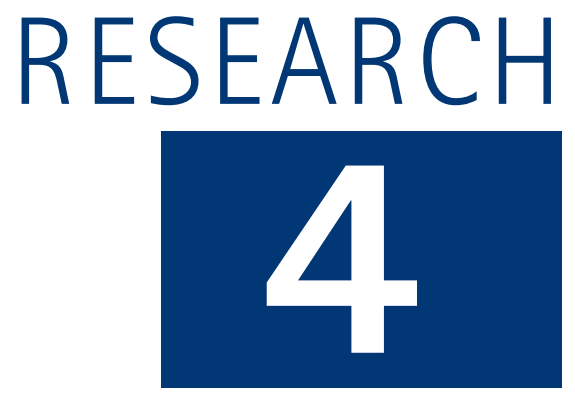

\title{
Oral health habits amongst children in the United Kingdom in 2003
}

\author{
D. A. White, ${ }^{1}$ B. L. Chadwick, ${ }_{1}^{2}$ N. M. Nuttall, ${ }^{3}$ I. G. Chestnutt ${ }^{4}$ and J. G. Steele ${ }^{5}$
}

\section{CHILDREN'S SURVEY}

1. The dentinal caries experience of children in the United Kingdom, 2003

2. Non-carious tooth conditions in children in the UK, 2003

3. Patterns of care and service use amongst children in the UK, 2003

4. Oral health habits amongst children in the United Kingdom in 2003

5. The reported impact of oral condition on children in the United Kingdom, 2003

6. The orthodontic condition of children in the United Kingdom 2003

Background The 2003 Children's Dental Health Survey is the fourth in a series of decennial national children's dental health surveys.

Aims This paper presents data on parental attitudes towards the care of children's teeth and gums, reported oral hygiene behaviours and clinical measures of hygiene and periodontal health in 2003 and highlights trends since previous surveys.

Method A total of 10,381 children were examined in schools by trained and calibrated examiners. Four measures of hygiene and periodontal health were recorded as part of the clinical examination. In addition, 3,342 questionnaires were completed by parents of a sub-sample of these children. The questionnaire enabled information to be collected about reported oral health behaviours and parental attitudes.

Results About three quarters of children across all age groups are reported to brush their teeth twice daily. A range of oral health products was reported as being used in addition to toothbrushes and toothpaste. There is a trend in parental preferences towards restoration of teeth

${ }^{1 *}$ Senior Lecturer in Dental Public Health, University of Birmingham; ${ }^{2}$ Reader/Hon consultant in Paediatric Dentistry, Cardiff University; ${ }^{3}$ Reader in Dental Public Health and Health Psychology, University of Dundee; ${ }^{4}$ Reader/Hon Consultant in Dental Public Health, Cardiff University; ${ }^{5}$ Professor in Oral Health Services Research, University of Newcastle *Correspondence to: Dr Deborah White, Dental Public Health, School of Dentistry, University of Birmingham, St Chad's Queensway, Birmingham B4 6NN Email:d.a.white@bham.ac.uk

\section{Refereed paper}

doi: $10.1038 /$ sj.bdj.4813586

() British Dental Journal 2006; 200: 487-491 rather than extractions and towards a better understanding of dental caries prevention. Although overall a higher proportion of children in this survey appeared to have gingival inflammation, plaque and calculus than 10 and 20 years ago, there was no change in the proportion of older children with gingivitis.

Conclusions Dental practitioners have a role to play in reinforcing these positive attitudes and encouraging appropriate and effective oral hygiene behaviours in their child patients.

\section{BACKGROUND}

The national surveys of Child Dental Health in the UK have provided a wealth of data about the oral health of children by means of a clinical dental examination and a parental questionnaire. In addition to identifying the current status of children's oral health in 2003, the use of consistent criteria since the inception of the surveys, back in 1973, enables us to identify trends over time. This paper presents data relating to three different but important areas of oral health which are linked to each other and which may give an indication of future health risks for this cohort. The areas covered are parental attitudes towards the care of children's teeth and gums, reported oral hygiene behaviours and clinical measures of hygiene and periodontal health.

The aim of this paper is to describe these aspects of children's oral health in 2003, and highlight any trends since previous surveys. The implications of these findings will be discussed in the context of their relevance to general dental practitioners.

\section{METHOD}

Full details of sampling, response, examination protocols and statistical methods can be found elsewhere. ${ }^{1}$ The 2003 survey was based on a representative sample of children aged five, eight, 12 and 15 years, attending government-maintained and independent schools in the UK. The survey involved 557 primary schools and 132 secondary schools. A total of 12,698 children were sampled within participating schools and asked to take part in a dental examination. In total 10,381 children were examined, a response rate of $82 \%$. The children who were examined were seen in their schools by trained and calibrated examiners using standardised measurement protocols. As part of the clinical protocol, periodontal health was recorded using criteria that were consistent with previous surveys in this series. Three of these, relating to the visual examination of the gingivae, recorded the 


\begin{tabular}{|c|c|c|c|c|c|c|c|c|c|c|c|c|c|c|c|c|}
\hline & \multicolumn{4}{|c|}{ 5-year-olds } & \multicolumn{4}{|c|}{ 8-year-olds } & \multicolumn{4}{|c|}{ 12-year-olds } & \multicolumn{4}{|c|}{ 15-year-olds } \\
\hline & $1973^{*}$ & 1983 & 1993 & 2003 & $1973^{*}$ & 1983 & 1993 & 2003 & $1973^{*}$ & 1983 & 1993 & 2003 & $1973^{*}$ & 1983 & 1993 & 2003 \\
\hline I, II, IIINM & - & 95 & 95 & 93 & - & 92 & 94 & 94 & - & 93 & 96 & 92 & - & 92 & 94 & 92 \\
\hline IIIM & - & 85 & 87 & 86 & - & 87 & 91 & 85 & - & 85 & 91 & 85 & - & 84 & 89 & 90 \\
\hline IV, V & - & 78 & 84 & 79 & - & 81 & 86 & 88 & - & 76 & 81 & 85 & - & 81 & 81 & 87 \\
\hline All & 88 & 88 & 86 & 88 & 88 & 87 & 88 & 90 & 87 & 86 & 89 & 89 & 85 & 87 & 88 & 89 \\
\hline
\end{tabular}

presence of gum inflammation, plaque and calculus by sextants of the mouth for all age groups. The fourth measure of periodontal health was used for 15-year-olds only. In this latter case a periodontal probe was used to detect gingival bleeding around six index teeth. Bleeding on probing is a marker of gingival inflammation. In order to ensure that there was no risk to the patient at all, this was only undertaken following negative response to a screening question: 'Do you carry a medical card or has anyone ever advised you to pass on any information to a dentist?' Periodontal pocketing was not measured, as accurate assessment of periodontal loss is difficult without a much more detailed and invasive examination. While destructive forms of periodontal disease can occur in adolescents, previous surveys had not identified periodontal attachment loss as a significant public health problem at this age. ${ }^{2}$

Questionnaires requesting background data on children's oral health behaviours, dental care, the impact of oral health and demographic data were sent to the parents of a random sub-sample of 5,480 examined children. In total, 3,342 questionnaires were returned, a response rate of $61 \%$. The questionnaire gathered information on reported attitudes and health behaviours which, when combined with the clinical data, help to give a fuller understanding of the whole picture of oral health.

Parents were asked, as in previous surveys, for their views on the cause and prevention of dental decay. Two questions have been asked since the inception of the surveys: 'What do you think makes teeth decay (or go bad)?' and 'What do you think can be done to stop teeth decaying (or going bad)?'. Their free-text responses were grouped into themes. Parents were also asked about whether they would prefer their child's permanent front or back tooth to be extracted or restored if it was decayed. Parents of the two younger ages were asked a similar question about baby teeth, including the option of leaving it alone.

Information from the questionnaire gives an indication of the way that children's teeth and oral health are maintained at home. As in previous surveys, questions were asked about reported tooth brushing and the use of fluoride supplements. In addition, the use of other oral health care products was investigated for the first time in 2003, providing an important baseline measurement.

It should be remembered that the information about oral health behaviours is reported for the children by their parents, with the exception of 15-year-olds who may have answered the questionnaire themselves.

In view of the complexity of the sampling design and resultant weighting procedures, sampling errors were quantified using the statistics programme STATA, and were calculated using a design factor (deft) to take account of the complex sampling and weighting procedures. The statistical significances of differences in means and percentages between sub groups were tested by calculating the confidence interval for the differences observed, based on the standard errors calculated using the design factor. This ensured that sampling error was taken into account in the testing procedure. Where statistically significant differences between groups are reported, the 5\% threshold $(\mathrm{p}<0.05)$ was used.

\section{RESULTS}

\section{Parental attitudes towards their children's dental care}

When asked about preventing tooth decay, 82\% of parents of five-year-olds compared with 73\% of respondents for 15 -yearolds believed that consumption of sweet and sugary foods was a major cause of tooth decay. Approximately two thirds of respondents, for all age groups, believed that poor oral hygiene was a major cause of tooth decay. Between $45 \%$ and 58\% of respondents indicated that avoiding sugar prevented tooth decay while $78 \%$ to $80 \%$ believed oral hygiene was important.

When treatment options for decay were considered, almost all parents preferred a restorative option for permanent front teeth whereas about $90 \%$ of parents overall preferred this option for permanent back teeth (Table 1). There were significant differences related to social class $(\mathrm{p}<0.05)$. For example, 93\% of five-yearolds' parents in social classes I, II \& IIInm preferred fillings compared with 79\% of parents from social class groups IV and V. The trend was the same for eight, 12 and 15-year-olds, but the difference associated with social class was smaller. There has been little change in the proportion of parents preferring a restorative option for permanent back teeth over 30 years.

Preferences for a decayed baby tooth were very different (Table 2), with just over a quarter of parents of five-year-olds preferring a filling (28\%), a similar proportion wishing to leave the tooth alone (31\%) and slightly more (40\%) preferring an extraction. A similar pattern was seen for eight-year-olds.

$\begin{aligned} & \text { Table } 2 \text { Parents' treatment preferences for their child's primary teeth } \\
& \text { (UK 2003) }\end{aligned}$
\begin{tabular}{lll} 
& $\mathbf{5}$ years & 8 years \\
& Percentage of parents preferring the tooth: \\
\hline Filled & 28 & 29 \\
Taken out & 40 & 39 \\
Left alone & 31 & 27 \\
Child has no baby teeth & 1 & 5
\end{tabular}

\section{Oral hygiene behaviours}

Parents had clearly associated oral hygiene and decay. Table 3 shows that most children and parents respond to that belief; about three quarters of children, across all age groups, are reported by respondents to brush their teeth twice daily. A small proportion is reported to brush more frequently than this and about a quarter, less often. However, there is some variation between boys and girls, with boys of all ages being significantly less likely to brush twice a day than girls $(p<0.05)$. Among eight-year-olds, $80 \%$ of girls brush twice daily compared with $73 \%$ of boys and among 15-year-olds, 79\% of girls brush twice daily compared with $70 \%$ of boys. In addition there are social class differences. A significantly higher proportion of children ( $p<0.05$ ) from high social class backgrounds (I, II and III nonmanual (nm)) are reported to brush twice daily, compared with their counterparts from low social class groups (IV and V). Seventy-nine per cent of 15-year-olds from social class I, II and IIInm backgrounds brush twice daily compared with 66\% from 
Table 3 Reported frequency of tooth brushing by age, sex and social class (United Kingdom, 2003)

$\begin{array}{lll}\text { Age } & \\ 5 & 8 & 12\end{array}$

All

Three times or more daily 2

Twice daily

76

76

Once daily or less

21

Weighted base

960

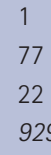

4

4

6

72

24

802

19

638

Boys

Three times or more daily

Twice daily

Once daily or less

74

24

460

1

2

70

28

430

5

70

24

329

Girls

Three times or more daily 3

Twice daily

Once daily or less

\section{8}

19

500

444

7

1

80

18

7

75

19

372

7

79

14

309

Social class I, II, III non-manual

Three times or more daily 3

Twice daily

Once daily or less

78

Weighted base

18

551

485

4

1

81

19

501

4

75

22

479

5

79

16

375

Social class III manual

Three times or more daily *

Twice daily

83

Once daily or less

83
16

Weighted base

177

2

70

4

4

6

70

24

130

Social class IV, V

Three times or more daily 2

Twice daily

$$
2
$$

60
38

133

191

174

6

$\begin{array}{lll}1 & 1 & 6 \\ 74 & 71 & 66 \\ 25 & 28 & 28 \\ 142 & 92 & 78\end{array}$

Weighted base

social class IV and V backgrounds. In comparison with previous surveys (Fig. 1) the proportion of children reported to brush twice a day has risen slightly in all age groups since 1993, although the increase is not as great as that reported over the 10 years following 1983. For example, in the 15-year-olds, three quarters reported to brush twice a day compared with $67 \%$ in 1993 ( $\mathrm{p}<0.05)$ and 46\% in 1983.

For the first time in 2003, questions were included about other products children used regularly for oral health. Figure 2 shows the proportion of children reported to use a variety of products ranging from traditional toothbrush and toothpaste to mouthwash and sugar free chewing gum.

The reported use of toothbrushes and toothpaste was almost universal. Although over $80 \%$ of children used a manual toothbrush, between $48 \%$ and $65 \%$ of children across the age groups reported using an electric toothbrush.

The use of disclosing tablets was reported by less than 10\% in all age groups and a small but an increasing proportion of children from five to 15 years were reported to use dental floss. Interestingly, almost half of the 15-year-olds reported that they used mouthwash. The use of sugar free or dental chewing gum was reported in all age groups, ranging from $12 \%$ of five-year-olds up to $44 \%$ of 15-year-olds.

The use of fluoride drops or tablets has been reported for between $1-2 \%$ of children in all age groups and this represents a significant reduction $(p<0.05)$ since 1993. Table 4 indicates a variation by country in 1993, with a higher proportion of children in Northern Ireland reported to use fluoride supplements than in

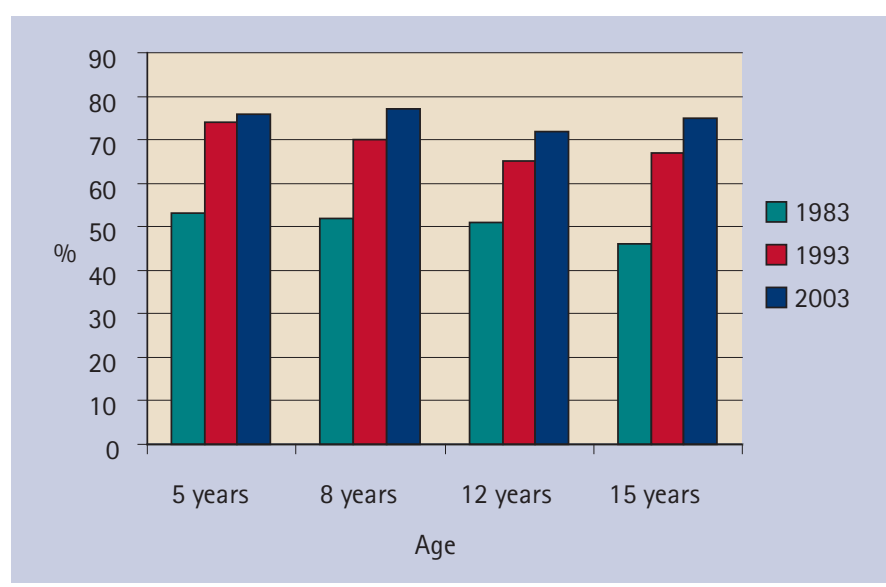

Fig. 1 Proportion of children reported to brush their teeth twice a day (United Kingdom 1983, 1993, 2003)

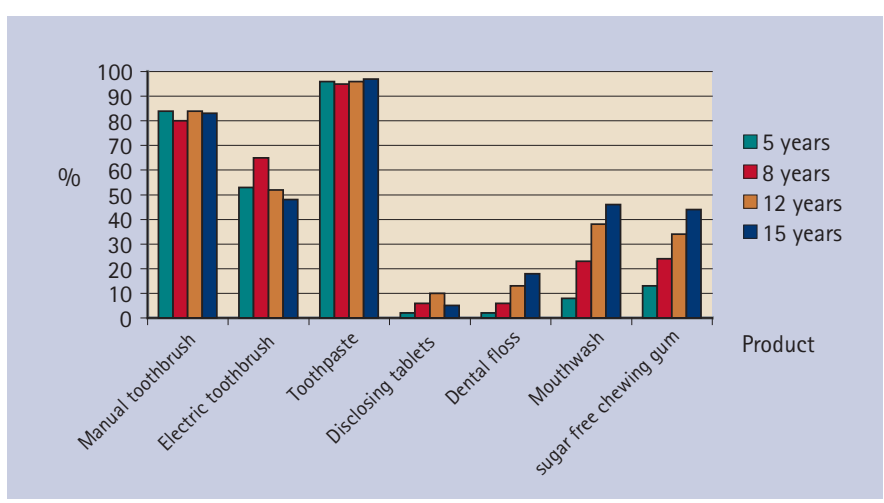

Fig. 2 Reported use of oral hygiene products by age (United Kingdom, 2003)

England and Wales. However, in 2003, the reported use of tablets and drops had fallen to similar low levels in all countries in the UK.

Parents of five and eight-year-old children were asked about who brushed their child's teeth. For about half of the five-yearolds and 15\% of eight-year-olds, an adult either brushed or helped with brushing of their teeth. The relationship between gingival health and responsibility for brushing is shown in Table 5. A significantly higher proportion ( $\mathrm{p}<0.05$ ) of five-year-old children who brushed unaided had plaque (52\%) and gingivitis (35\%) than those who had adult help (44\% and 29\%).

\section{Clinical measures of oral hygiene and periodontal health}

Data in this section are drawn from the clinical examination so the sample sizes are larger than in the previous sections. Overall, a higher proportion of children in this survey appeared to have gingival inflammation, plaque and calculus than 10 and 20 years ago. Table 6 shows that the pattern with age was the same for gingival inflammation and plaque, with a significantly higher proportion of children aged eight and 12 years affected $(p<0.05)$, than their younger and older counterparts. For example, only about a third (32\%) of five-year-olds had gingival inflammation compared with almost two thirds (63\% and 65\%) of eight and 12year-olds and about half (52\%) of the oldest children, aged 15. The proportion of children with calculus increased with increasing age from $6 \%$ of five-year-olds to 39\% of 15-year-olds.

For each of the above indicators, there was no statistically significant difference between boys and girls, except among 15-year-olds, where $68 \%$ of boys had plaque and 56\% inflammation, compared with 57\% of girls with plaque and 48\% with inflammation ( $\mathrm{p}<$ 0.05). Schools taking part in the survey were classified as 'deprived' or 'non-deprived' based on the proportion of children receiving free school meals. There were no statistically significant differences due 
Table 4 The proportion of five and eight year olds reported as using fluoride supplements (UK 1993, 2003)

\begin{tabular}{|c|c|c|c|c|c|c|c|c|}
\hline & \multicolumn{2}{|l|}{ 5-year-olds } & \multicolumn{2}{|c|}{ 8-year-olds } & \multicolumn{2}{|c|}{ 12-year-olds } & \multicolumn{2}{|c|}{15 -year-olds } \\
\hline & 1993 & 2003 & 1993 & 2003 & 1993 & 2003 & 1993 & 2003 \\
\hline England & 6 & 2 & 4 & 1 & 2 & 2 & 3 & 1 \\
\hline Wales & 10 & 2 & 6 & 4 & 4 & 1 & 3 & - \\
\hline N. Ireland & 33 & 6 & 22 & 3 & 22 & 3 & 10 & 2 \\
\hline U.K. & 9 & 2 & 6 & 1 & 3 & 2 & 3 & 1 \\
\hline
\end{tabular}

\begin{tabular}{|c|c|c|}
\hline & $\begin{array}{l}\text { Who brushes teeth } \\
\text { Child }\end{array}$ & Adult or adult $\mathbb{E}$ child together \\
\hline & $\begin{array}{l}50 \% \\
\text { percentage of children }\end{array}$ & $\begin{array}{l}50 \% \\
\text { with: }\end{array}$ \\
\hline Gingivitis & 35 & 29 \\
\hline Plaque & 52 & 44 \\
\hline Calculus & 6 & 6 \\
\hline Weighted base & 487 & 491 \\
\hline
\end{tabular}

to school deprivation status for any of the periodontal indicators, except among eight-year-olds, where a significantly lower proportion of children in deprived schools (54\%) had inflamed gums than those in non-deprived schools $(65 \%)(\mathrm{p}<0.05)$. There was, however, some variation between countries; a significantly lower proportion ( $p<0.05)$ of children in Wales had plaque, calculus and gum inflammation in all age groups than in England and Northern Ireland.

Fifteen-year-old children were examined for gingival bleeding and results are presented for individual teeth in Table 7. A significantly higher proportion of children had gingivitis around their lower molar teeth than their upper molars or incisors $(p<0.05)$. There has been a slight reduction for all sites since 1993 .

\section{DISCUSSION}

Data gathered from the questionnaire provide an insight into parental attitudes and beliefs about their children's teeth and how these have changed since the first survey of children's dental health in 1973. Previous surveys have identified discordance between parental beliefs about the causes of tooth decay and the way in which it can be prevented. ${ }^{2}$ To a lesser extent this is apparent here too. More parents identify sugar and sweet things as causes of decay than identify avoidance of sweet things as a means to prevent it. More people saw tooth brushing as important when the prevention of tooth decay was considered. There is still a significant minority of parents who do not recognise sugary foods as a decay risk for children.

The responses in this survey show a similar pattern to that shown in $1993^{3}$ with similar beliefs operating. However, a smaller proportion of all parents in 2003 indicate that visiting the dentist might have a part to play in preventing dental decay than parents 10, 20 and 30 years ago. ${ }^{4,5}$ For example, only 16\% of five-yearolds' parents and 22\% of 15-year-olds' parents believed this could prevent decay compared with 25\% and 29\% in 1993 ( $p<0.05)$.

The difference between the proportion of parents preferring restoration of front and back permanent teeth is unsurprising and reflects the differing aesthetic impact that the loss of these teeth might have. There has been little change in these preferences since 1973, which suggests that there is no evidence for increase in

demand or expectations in the last 30 years regarding restoration of children's permanent teeth. Social class differences are apparent in 2003, which are also similar to those observed in previous surveys.

As primary teeth are shed naturally, there is a tendency for parents to place little value on them, despite their benefit for space maintenance. The reported treatment preferences for baby teeth substantiate this, as over a third of parents of five-year-old children would prefer an extraction to a filling. A further 31\% indicate that they would leave the tooth alone, and may be ignorant of the possibility that it may be a focus for pain and infection. ${ }^{6}$ However, even members of the dental profession have differing treatment philosophies regarding primary teeth: paediatric dentistry specialists may advocate restorations while general dental practitioners may have a less interventionist approach, ${ }^{7}$ so perhaps this variation in parental opinion is perfectly understandable. It has been suggested that there may be no advantage under existing General Dental Service regulations in filling carious primary teeth over leaving them unrestored, as both options are equally likely to result in an extraction. ${ }^{8}$ Comparing data for England and Wales with that from the 1973 survey, it appears that parents in 2003 are less likely to opt for treatment of a baby tooth, either by extraction or restoration than they were 30 years ago, when about half the parents said they would prefer an extraction and just over a third, a filling.

The way in which children take care of their mouths at home is an important part of maintaining good oral health. The recommended frequency of tooth brushing is twice a day (with a fluoride toothpaste) and it is also suggested that children under the age of seven years need help with brushing in order to carry it out effectively. ${ }^{9}$ It would appear that the message about frequency has been taken on board by parents of children in this survey, as over three quarters of the children in all age groups were reported as brushing at least twice a day. The second message has not been as effectively received as only half the five-year-old children had help with their brushing from an adult, the remainder preferred to be independent and brush unaided. As the children who were helped to brush had less plaque and gingival inflammation in this survey it would appear to be important that members of the dental team reinforce this message when discussing tooth brushing with families.

The use of electric toothbrushes appears to be widespread, with between about half and two thirds of all children reporting their use. Research has shown that certain types of powered brushes demonstrate a modest clinical benefit over manual toothbrushes. ${ }^{10}$

The reported use of mouthwash increased with age and was used by $46 \%$ of 15-year-olds. A wide variety of mouthwashes are now available for home use, which may contain fluoride as well as chemical plaque suppressants. Information about the type of mouthwash and reason for use was not elicited from parents in this survey. Despite the efficacy of some mouthwashes in improving oral hygiene

\begin{tabular}{|c|c|c|c|c|c|c|c|c|c|}
\hline \multirow[t]{2}{*}{ Age } & \multicolumn{3}{|c|}{ Gum inflammation } & \multicolumn{3}{|l|}{ Plaque } & \multicolumn{3}{|c|}{ Calculus } \\
\hline & 1983 & 1993 & 2003 & 1983 & 1993 & 2003 & 1983 & 1993 & 2003 \\
\hline & \multicolumn{9}{|c|}{ Percentage of children: } \\
\hline 5 & 19 & 26 & 32 & 29 & 45 & 50 & 3 & 5 & 6 \\
\hline 8 & 46 & 58 & 63 & 55 & 70 & 76 & 13 & 16 & 23 \\
\hline 12 & 49 & 60 & 65 & 48 & 68 & 73 & 21 & 20 & 30 \\
\hline 15 & 48 & 52 & 52 & 47 & 57 & 63 & 33 & 32 & 39 \\
\hline
\end{tabular}




\begin{tabular}{|c|c|c|c|c|c|c|c|}
\hline & $\begin{array}{l}\text { Upper } \\
\text { right } 6\end{array}$ & $\begin{array}{l}\text { Upper } \\
\text { right } 1\end{array}$ & $\begin{array}{l}\text { Lower } \\
\text { right } 6\end{array}$ & $\begin{array}{l}\text { Upper } \\
\text { left } 6\end{array}$ & $\begin{array}{l}\text { Lower } \\
\text { left } 1\end{array}$ & $\begin{array}{l}\text { Lower } \\
\text { left } 6\end{array}$ & Any tooth \\
\hline & \multicolumn{7}{|c|}{ Percentage of 15-year-olds with some gingivitis: } \\
\hline 2003 & 15 & 13 & 23 & 15 & 13 & 21 & 43 \\
\hline 1993 & 19 & 14 & 24 & 18 & 16 & 24 & 45 \\
\hline
\end{tabular}

status and gingival health, ${ }^{11}$ their use is not recommended in young children until they are able to spit effectively. Additionally, ethanolcontaining products are not advised for children's long-term use for safety reasons. ${ }^{12}$ It may be therefore of some concern that just under $10 \%$ of five-year-old children in this survey were reported as using mouthwash, particularly if, like their reported tooth brushing, it is sometimes without an adult present. The increasing trend towards use of mouthwash as an oral health aid in adults over the past 20 years has been identified in the $\mathrm{UK}^{13}$ and this trend may also be mirrored in children, but as data relating to usage were collected for the first time in 2003, it is not possible to confirm this.

The reported use of fluoride supplements since 1993 has decreased throughout the UK, despite there still being a small variation between countries. In 1997, following an extensive review of the literature, new guidelines were produced by the British Society of Paediatric Dentistry relating to the dosage of fluoride supplements and their usage for children at risk from dental caries rather than as a public health measure. ${ }^{4,15}$ The decreasing use shown in this survey would seem to reflect these national policy guidelines.

The high usage of sugar free gum is an interesting finding and may be more significant than it at first seems. Unfortunately we have no earlier data with which we can compare, but empirically its use would seem to have increased substantially over the last two decades. It is effective in stimulating salivary flow so if used after food or as an alternative to sweet foods it can be effective in modifying caries risk. ${ }^{16,17}$ Furthermore some sugar free gums contain xylitol as a sugar substitute. This appears to be effective in caries management in its own right by direct action on the oral microflora responsible for caries. ${ }^{18,19}$ To what extent sugar free gum may have played a part in continued reductions in adolescent decay is completely unknown, but a relationship is feasible based on the extent of recent usage.

Although general awareness of oral hygiene and oral healthcare products appears to have improved since previous surveys, this does not mean that teeth are cleaned effectively. Superficially there appears to have been a worsening of oral hygiene and gingival health since 1983 using visual assessment. However, the results of probing in 15-year-olds appear to contradict this and seem to show a slight improvement at individual tooth sites. Examiner variation may have contributed to these findings and also to the apparent difference in prevalence between the three countries. Obtaining examiner reproducibility for plaque and to a lesser degree, gingivitis, is notoriously difficult. The precise trajectory of the trend may be uncertain but it would appear that it is at least safe to say that we have seen no major improvement since 1993.

The finding that almost two thirds of eight and 12-year-olds have gingival inflammation indicates that plaque control at this early age is often not particularly effective, and this is despite the generally reported good hygiene habits reported in the previous section. Plaque-induced chronic gingivitis in children can be managed by mechanical removal of plaque and good oral hygiene ${ }^{20}$ and good hygiene should have further benefits in terms of caries risk. Dental practitioners and other members of the dental team have an important role in developing effective hygiene practices at an early stage through education of parents and children. Finding effective ways of getting the message across is a challenge, but plaque removal and oral hygiene techniques should be part of routine preventive care for every child.

\section{CONCLUSIONS}

Parental understanding about the causes of decay generally indicate that the association between dietary sugars and caries is well understood at the population level, though there remains a small but significant group who appear ignorant of the link. There has been little change in parental attitudes towards restoration of permanent teeth, where the majority prefer a restorative option. This is not reflected in the primary dentition where parents would still often rather not opt for a restoration.

There appears to be an increasing awareness of oral health among parents of all age groups of children, which is demonstrated by the reported tooth brushing behaviours and also the use of a range of oral hygiene products, and is a very positive development. The variation in behaviour related to social class may be a concern.

There is no clear evidence for a concurrent improvement in plaque control. There has been an apparent worsening of gingival condition and hygiene since 1993, though when looking specifically at gingivitis in 15-year-olds there are signs of slight improvement. We may need to wait until the next survey to establish if there really is any overall change.

There is still much to be done if we are to optimise prevention of dental disease for children. It is perhaps a reflection of the way that dentists are viewed, that fewer parents in 2003 than 10 years earlier saw a visit to the dentist as playing an important role in prevention. Public health and general health promotion have their parts to play, but dental practitioners and members of the dental team are still in the front line, supporting a positive parental attitude towards maintaining good oral health for their children and encouraging appropriate treatment.

This work was undertaken by a consortium comprising the Office for National Statistics and the Dental Schools of the Universities of Birmingham, Cardiff, Dundee and Newcastle and the Dental health Services Research Unit, Dundee, who received funding from the United Kingdom Health Department; the views expressed in this publication are those of the authors and not necessarily those of the Health Department.

1. Pendry L, Lashkari G, Bewley H. Technical Report: 2003 Children's Dental Health Survey. London Office for National Statistics, 2004.

2. O'Brien M. Children's dental health in the United Kingdom 1993. London: HMSO, 1994.

3. White D, Lader D. Periodontal condition, hygiene behaviour and attitudes to oral health. Children's Dental Health in the United Kingdom, 2003. London: Office for National Statistics, 2004.

4. Todd J E, Dodd T. Children's dental health in the United Kingdom, 1983. London: HMSO, 1985.

5. Todd J E. Children's dental health in England and Wales, 1973. London: HMSO, 1975.

6. Levine R S, Nugent Z J, Pitts N B. Pain prediction for preventive non-operative management of dentinal caries in primary teeth in general dental practice. Br Dent $J$ 2003: 195: 202-206

7. Tickle M, Milsom K, King D et al. The fate of the carious primary teeth of children who regularly attend the general dental service. Br Dent J 2003; 192: 219-223.

8. Tickle M, Milsom K, Kennedy A. Is it better to leave or restore carious deciduous molar teeth? A preliminary study. Primary Dent Care 1999; 6: 127-131.

9. Levine R S, Stillman-Lowe C R. The scientific basis of oral health education. London: British Dental Association, 2004.

10. Deery $\mathrm{C}$. Heanue M, Deacon $\mathrm{S}$ et al. The effectiveness of manual versus powered toothbrushes for dental health: a systematic review. J. Dent 2004; 32: 197-211.

11. Axelsson $\mathrm{P}_{1}$ Lindhe J. Efficacy of mouthrinses in inhibiting dental plaque and gingivitis in man. J Clin Periodonto/ 1987; 14: 205-212.

12. FDI commission. Mouthrinses and dental caries. Int Dent J 2002; 52: 337-345

13. Bradnock G, White D A, Nuttall N M et al. Dental attitudes and behaviours in 1998 and implications for the future. Br Dent J 2001 190: 228-232.

14. British Society of Paediatric Dentistry: A policy document on fluoride dietary supplements and fluoride tooth pastes for children. Int J Paed Dent 1996; 6: 139-142.

15. BDA, BSPD, BASCD. Fluoride supplement dosage. Br Dent J 1997; 182: 6-7.

16. Machiulskiene $V$, Nyvad B, Baelum V. Caries preventive effect of sugar-substituted chewing gum. Comm Dent Oral Epidemio/ 2001; 29: 278-288.

17. Beiswanger $B$ B, Boneta $A E_{1}$ Mau M S et al. The effect of chewing sugar-free gum after meals on clinical caries incidence. J Am Dent Assoc 1998; 129: 1623-1626.

18. Makinen K K, Bennett C A, Hujoel P P et al. Xylitol chewing gums and caries rates: a 40-month cohort study. J Dent Res 1995; 74: 1904-1913.

19. Twetman S, Stecksen-Blicks C. Effect of xylitol-containing chewing gums on lactic acid production in dental plaque from caries active pre-school children. Oral Health Prev Dent 2003; 1: 195-199.

20. Oh $T$, Ebar $R$, Wang $H$. Periodontal diseases in the child and adolescent. J Clin Periodontol 2002; 29: 400-410. 